\title{
Responsiveness of the maximum time-varying elastance to alterations in left ventricular contractile state in man
}

\begin{abstract}
This investigation was designed to establish the relative responsiveness of maximum time-varying elastance $\left(E_{\max }\right.$ ) slope values to alterations in left ventricular contractile state in comparison wilh isovolumic and ejection phase indices in man. Accordingly, nine patients had a bipolar right atrial pacing catheter and micromanometer left ventricular catheter placed and red blood cells tagged with technetium-99m for radionuclide angiography. Hemodynamic measurements and radionuclide angiograms were acquired simultaneously over a range of loading conditions produced by methoxamine or nitroprusside infusions during both the basal and enhanced contractile states. Enhanced left ventricular contractility was produced by a steady-state dobutamine infusion of 2 to $10 \mu / \mathrm{kg} / \mathrm{min}$. The mean ( $+\mathrm{dP} / \mathrm{dt}_{\max }$ increased from $1510 \pm 460 \mathrm{~mm} \mathrm{Hg} / \mathrm{sec}$ during the basal state to $2537 \pm 546 \mathrm{~mm} \mathrm{Hg} / \mathrm{sec}(p<0.001)$ during the dobutamine infusion. The mean $E_{\max }$ slope value also increased from $4.34 \pm 1.40 \mathrm{~mm} \mathrm{Hg} / \mathrm{ml}$ during the basal state to $6.41 \pm 1.90 \mathrm{~mm}$ $\mathrm{Hg} / \mathrm{ml}(p<0.001)$ during the dobutamine infusion. The average percent change in the $E_{\max }$ slope value $(51 \pm 26 \%)$ was less than those for the isovolumic indices $(57 \%$ to $112 \%)$, while it was more than those for the ejection phase indices ( $11 \%$ to $53 \%$ ). When the variability in the percent changes for each of these contractile indices was incorporated into the analysis, the $E_{\max }$ slope values demonstrated a greater responsiveness to changes in left ventricular contractility than did the isovolumic and ejection phase indices. In conclusion, the $E_{\max }$ slope value calculated by this method is a contractile index, which is less affected by measurement variability and the influences of loading conditions than are the isovolumic and ejection phase indices, and therefore may improve our ability to both detect and quantitate changes in left ventricular contractility in man. (AM HEART J 1989;118:1266.)
\end{abstract}

Mark R. Starling, MD. Ann Arbor, Mich.

An "ideal" left ventricular contractile index should be a measurement that provides a reflection of basal or altered inotropic states; also, it should not be affected by confounding influences, e.g., loading conditions and measurement errors, which may introduce significant variability into the left ventricular contractile index calculation. The time-varying relationship between left ventricular pressure $(\mathrm{P})$ and volume (V) has been proposed as such a measure-

From the Department of Internal Medicine, Division of Cardiology, University of Michigan, and VA Medical Centers.

Supported by National Institutes of Health grant No. R01-HL36450 from the National Heart, Lung, and Blood Institute, Bethesda, Md., and by the Veterans Administration, Washington, D.C. Dr. Starling is the recipient of NIH Research Career Development Award No. K04-HL01787 from the National Heart, Lung, and Blood Institute, Bethesda, Md.

Received for publication Jan. 3, 1989; accepted July 14, 1989.

Reprint requests: Mark R. Starling, MD, University of Michigan, Dept. of Medicine, Division of Cardiology, VA Medical Center, 2215 Fuller Rd., Ann Arbor, MI 48105 .

4/1/15929 ment of left ventricular contractility. ${ }^{1-3}$ This concept characterizes left ventricular contractility by both a slope and volume-axis intercept calculated from multiple P-V data points obtained over a range of loading conditions. The left ventricle demonstrates ever-increasing slope values from the onset of electromechanical systole until a maximum slope, i.e., the maximum elastance $\left(\mathrm{E}_{\max }\right)$, is achieved. ${ }^{2}$ Left ventricular chamber elastance has been calculated in man with both cineventriculography ${ }^{4}$ and radionuclide angiography ${ }^{5,6}$ under basal contractile conditions. The clinical utility of the elastance concept may reside, however, in its ability to detect and quantitate alterations in left ventricular contractility in man. The responsiveness of $E_{\max }$ slope values to alterations in left ventricular contractility compared with isovolumic and ejection phase indices has not been defined in man. Since the calculation of $E_{\max }$ slope values during basal and enhanced contractile states necessitates that multiple P-V data points be obtained over a range of loading conditions to char- 
acterize this relationship by both a slope and volumeaxis intercept, it is difficult to do so using cineventriculography. In contrast, this is not a limitation of radionuclide angiography where multiple data acquisitions may be easily performed. Accordingly, the purpose of this investigation was to define the responsiveness of $\mathrm{E}_{\max }$ slope values calculated with radionuclide angiography to alterations in left ventricular contractility compared with isovolumic and ejection phase indices in man.

\section{METHODS}

Patients. 'The study population consisted of nine patients, who were referred for diagnostic cardiac catheterization to evaluate atypical chest pain. Their ages ranged from 33 to 71 years (mean $52 \pm 12$ [SD] years). All patients also had a normal physical examination, chest $\mathrm{x}$-ray films, electrocardiogram, and M-mode echocardiographic study. All medications were discontinued 24 to 48 hours prior to the cardiac catheterization. Each patient gave written informed consent for this investigation on forms approved by the Human Studies Committees at the University of Michigan or Veterans Administration Medical Centers, Ann Arbor, Mich.

Protocol. After a diagnostic left-sided heart catheterization had documented normal coronary anatomy and left ventricular performance, each patient entered the protocol. The protocol was designed to simultaneously acquire micromanometer left ventricular pressures and radionuclide angiograms over a range of loading conditions during basal and enhanced contractile states. The latter was produced by a steady-state, intravenous infusion of dobutamine ( 2 to $10 \mu \mathrm{g} / \mathrm{kg} / \mathrm{min}$ ) to achieve a range of altered contractile states in these patients. During the basal and enhanced contractile states, a control acquisition was followed by two additional acquisitions during methoxamine or nitroprusside infusions. A stable hemodynamic state was considered present for each loading condition when left ventricular systolic pressure varied by less than $10 \mathrm{~mm} \mathrm{Hg}$. The methoxamine infusions ranged between 200 and 733 $\mu \mathrm{g} / \mathrm{min}$, and the nitroprusside infusions ranged from 8 to 78 $\mu \mathrm{g} / \mathrm{min}$. Importantly, one of the nine patients had only two acquisitions during the enhanced contractile state, and a different patient had only two acquisitions during the enhanced contractile state because of technical problems with the radionuclide data acquisition.

Hemodynamics. A bipolar pacing catheter was placed in the right atrium to maintain a constant heart rate during the entire protocol and thus to avoid the affects of heart rate changes on left ventricular contractility. ${ }^{7}$ 'This necessitated pacing at approximately 10 to 15 beats/min higher than the resting heart rate during the basal contractile state so that the chronotropic response to dobutamine would not result in a heart rate that exceeded that in the basal contractile state. Through the right femoral artery, a micromanometer catheter (VPC-780C or VPC-784D,
Millar Instruments, Houston, Texas) was positioned to measure left ventricular pressures. Hemodynamic recordings were obtained with an Electronics for Medicine VR12 physiologic recorder (PPG Biomedical Systems, Pleasantville, N.Y.) at $100 \mathrm{~mm} / \mathrm{sec}$ paper speed. These recordings routinely included two electrocardiographic leads, micromanometer left ventricular pressures (40 and $200 \mathrm{~mm}$ $\mathrm{Hg}$ scales), and the first derivative of left ventricular pressure $(\mathrm{dP} / \mathrm{dt})$, obtained by continuous electronic differentiation of the left ventricular pressure signal. These hemodynamic recordings were made for 20 cardiac cycles at the beginning, middle, and end of each radionuclide acquisition.

The left ventricular pressure waveforms were averaged for each of the loading conditions during the basal and enhanced contractile states. The average left ventricular pressure waveforms were then hand digitized using a Calcomp 9100 inductance digitizing surface (resolution 0.02 $\mathrm{mm}$ ) interfaced to an IBM PC computer (IBM Corp., Purchase, N.Y.). The programs developed in our laboratory yield instantaneous left ventricular pressures and $\mathrm{dP} / \mathrm{dt}$ at 5 msec intervals from the peak of the $R$ wave of the simultaneously recorded electrocardiogram. ${ }^{4,6}$ Interpolation of these hand-digitized left ventricular pressure data was performed to guarantee isochronicity of the pressurevolume data.

Radionuclide angiography. Gated equilibrium radionuclide angiograms were obtained following in vivo red blood cell labeling with $30 \mathrm{mCi}$ of technetium-99m for $30 \mathrm{msec}$ frames throughout the R-R interval for 500 cardiac cycles. During the middle of each radionuclide acquisition, a $2 \mathrm{ml}$ blood sample was drawn. These blood samples were later counted for 2 minutes and the time delay between acquisition and counting of the blood samples was recorded. At the end of the protocol, distance measurements were made for each patient to calculate the distance from the center of the left ventricle to the gamma camera using a simple geometric approach. ${ }^{8-10}$

Attenuation-corrected radionuclide left ventricular volumes were calculated frame by frame using backgroundsubtracted, hand-drawn region-of-interest left ventricular count data. These left ventricular counts were standardized for frame duration, cardiac cycles acquired, decaycorrected blood samples counts, and then wcre attenuation corrected as previously validated in this laboratory. ${ }^{8,9}$

Definitions and calculations. Several definitions are important to the calculation of the commonly used isovolumic and ejection phase indices. ${ }^{11}$ Left ventricular enddiastolic volume (EDV) was defined as the maximum ventricular volume, which usually occurred on the initial frame of the radionuclide left ventricular volume curve. Left ventricular end-systolic volume (ESV) was defined as the minimum ventricular volume obtained from the radionuclide left ventricular volume curve. The systolic ejection period (SEP) was then defined as the time from the peak of the QRS complex to minimum ventricular volume.

Using these definitions, several isovolumic and ejection 
BASELINE CONTRACTILE STATE

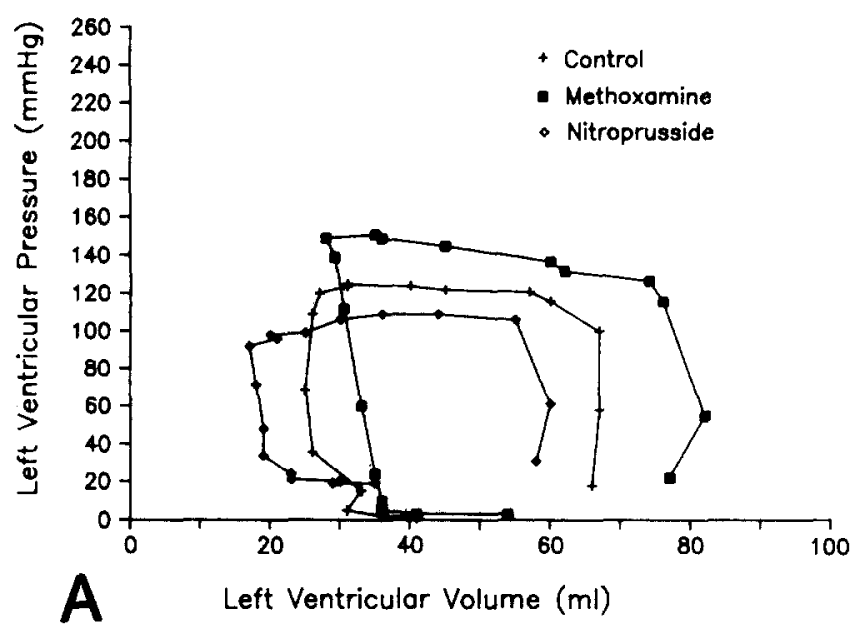

ENHANCED CONTRACTILE STATE

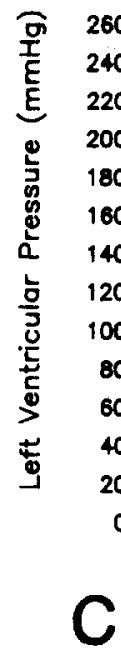

FIg. 1. A, The pressure-volume loops obtained from the hand-digitized average left ventricular pressure waveforms and the corresponding radionuclide left ventricular volumes under basal contractile conditions are illustrated. $\mathrm{B}$, The isochronal $\mathrm{E}_{\max }$ slope, extrapolated volume-axis intercept $\left(V_{0}\right)$, and correlation coefficient are shown. $C$, The pressure-volume loops obtained from the hand-digitized average left ventricular pressure waveforms and the corresponding radionuclide left ventricular volumes during the dobutamine infusion are shown. $D$, The isochronal $E_{\max }$ slope, $V_{0}$, and correlation coefficient are shown. phase indices were calculated. The $(+) \mathrm{dP} / \mathrm{dt}_{\max }$ was defined as the maximum rate of change in left ventricular pressure obtained from the hand-digitized left ventricular pressure waveform. ${ }^{4,6,8,11}$ To potentially eliminate the load dependence of this measure of left ventricular contractility, ${ }^{11-13}$ the $(+) \mathrm{dP} / \mathrm{dt}_{\max }$ was standardized to left ventricular end-diastolic volume $\left[(+) \mathrm{dP} / \mathrm{dt}_{\max } / \mathrm{EDV}\right]$ and $(+) \mathrm{dP} / \mathrm{dt}$ at a common developed pressure of $40 \mathrm{~mm} \mathbf{H g}$ was used $\left[(+) \mathrm{dP} / \mathrm{dt} / \mathrm{DP}_{40}\right]$. Left ventricular stroke volume was defined as the difference between left ventricular EDV and ESV. Left ventricular ejection fraction (EF) was then calculated as the stroke volume divided by left ventricular EDV and multiplied by 100 . The mean systolic ejection rate (MSER) was calculated by dividing the left ventricular stroke volume by the systolic ejection period (SEP). Left ventricular stroke work (SW) was calculated as the integrated area obtained by calibrated planimetry of the left ventricular P-V loop. ${ }^{11}$ 'I'his area was then divided by body surface area in square meters and multiplied by 0.0136 to convert from $\mathrm{mm} \mathrm{Hg} \times \mathrm{ml} / \mathrm{m}^{2}$ to gram-meters $/ \mathrm{m}^{2}{ }^{14}$ This left ventricular SW index was then standardized to the corresponding left ventricular end-diastolic volume by dividing by EDV (SW/EDV).

The radionuclide left ventricular maximum time-varying elastance was calculated as previously described. ${ }^{4-6}$ Corresponding P-V data points were plotted for each loading condition during the basal and enhanced contractile states to produce P-V loops, as shown for a representative 
Table I. Control hemodynamic data $(N=9)$

\begin{tabular}{|c|c|c|c|c|c|c|}
\hline Patient No. & $\begin{array}{c}H R \\
\text { (beats } / \mathrm{min} \text { ) }\end{array}$ & $\begin{array}{c}L V P \\
(m m H g)\end{array}$ & $\begin{array}{l}\text { LVEDP } \\
(m m \mathrm{Hg})\end{array}$ & $\begin{array}{l}(+) d P / d t_{\max } \\
(m m \mathrm{Hg} / \mathrm{sec})\end{array}$ & 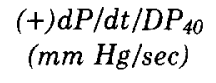 & $\begin{array}{c}E_{\max } \\
(m m \mathrm{Hg} / \mathrm{ml})\end{array}$ \\
\hline 1 & 89 & 101 & 9 & 1046 & 751 & 5.18 \\
\hline 2 & 79 & 172 & 14 & 1266 & 1237 & 2.99 \\
\hline 3 & 89 & 156 & 11 & 1416 & 1035 & 2.21 \\
\hline 4 & 90 & 151 & 10 & 1786 & 1084 & 5.71 \\
\hline 5 & 73 & 128 & 20 & 1393 & 935 & 5.06 \\
\hline 6 & 100 & 76 & 6 & 1100 & 1099 & 4.25 \\
\hline 7 & 80 & 142 & 10 & 2065 & 1438 & 6.64 \\
\hline 8 & 94 & 175 & 6 & 2360 & 1441 & 3.23 \\
\hline 9 & 84 & 124 & 7 & 1164 & 1110 & 2.50 \\
\hline$\overline{\mathrm{X}}$ & $\overline{85}$ & $\overline{136}$ & $\overline{11}$ & $\overline{1510}$ & $\overline{1121}$ & $\overline{4.34}$ \\
\hline SD & \pm 8 & \pm 33 & \pm 5 & \pm 460 & \pm 195 & \pm 1.40 \\
\hline
\end{tabular}

HR, Heart rate; LVP, left ventricular systolic pressure; LVEDP, left ventricular end-diastolic pressure; $(+) \mathrm{dP} / \mathrm{dt}$ max, maximum rate of change of left ventricular pressure; $(+) \mathrm{dP} / \mathrm{dt} / \mathrm{DP}_{40},(+) \mathrm{dP} / \mathrm{dt}$ at a developed pressure of $40 \mathrm{~mm} \mathrm{Hg}$; $\mathrm{E}_{\max }$, maximum time-varying elastance slope value.

patient in Fig. 1. Then isochronal, instantaneous P-V data points from each loading condition were subjected to linear regression analysis beginning at the peak of the $R$ wave every $30 \mathrm{msec}$ for 20 sequential frames. The maximum slope for these isochrones was defined as the left ventricular maximum time-varying elastance $\left(\mathrm{E}_{\max }\right)$ and the extrapolated volume-axis intercept for this isochrone was defined as $V_{0}$. The time to $\mathrm{E}_{\max }$ was defined as $\mathrm{T}_{\max }$. These measures of left ventricular elasticity, $E_{\max }, V_{0}$, and $T_{\text {max }}$, were calculated for both the basal and enhanced contractile states as shown for a representative patient in Fig. 1.

Statistical analysis. To establish whether stable contractile states were present over the range of loading conditions generated during the basal and enhanced contractile states, the hemodynamic measurements obtained during each loading condition for both contractile states were compared by a repeated measures analysis of variance. When a significant $F$ statistic was obtained, $t$ tests with a Bonferroni correction were used to identify differences. Comparisons between hemodynamic parameters during the basal and enhanced contractile states were performed by paired $t$ tests. The percent changes from the basal to the enhanced contractile state were calculated for the isovolumic and ejection phase indices and the $\mathrm{E}_{\max }$ slopes. Then the mean percent changes were compared by an analysis of variance. When a significant $F$ statistic was obtained, $t$ tests with a Bonferroni correction were performed to identify where differences existed. Moreover, the percent changes in the $E_{\max }$ slope values were compared with the corresponding percent changes in the isovolumic and ejection phase indices using correlation matrices and multiple regression analyses. A probability value of 0.05 or less was required to achieve significance for all comparisons.

\section{RESULTS}

Hemodynamic data. The control hemodynamic data for each of the nine patients included in this investigation are shown in Table $I$, and the changes in these hemodynamic data from the basal to the enhanced contractile state are shown in Fig. 2. Notably, due to right atrial pacing there was no significant difference in the mean heart rates during the basal and enhanced contractile states $(88 \pm 8$ versus $90 \pm 11 \mathrm{beats} / \mathrm{min}$ ). Similarly, there was no significant difference between the left ventricular enddiastolic pressures during the two contractile states $(11 \pm 5$ versus $10 \pm 4 \mathrm{~mm} \mathrm{Hg})$. In contrast, there was a significant increase in the left ventricular peak systolic pressure from $136 \pm 33$ to $170 \pm 27 \mathrm{~mm} \mathrm{Hg}$ $(p<0.01)$ and in $(+) \mathrm{dP} / \mathrm{dt}_{\max }$ from $1510 \pm 460$ to $2537 \pm 546 \mathrm{~mm} \mathrm{Hg} / \mathrm{sec}(p<0.001)$. Both the left ventricular end-diastolic and end-systolic volumes decreased from $120 \pm 48$ and $55 \pm 36 \mathrm{ml}$ during the basal contractile state to $103 \pm 34$ and $41 \pm 25 \mathrm{ml}$ during the enhanced contractile state ( $p=$ NS and $p<0.05$, respectively).

Over the range of loading conditions generated during the basal and enhanced contractile states, stable contractile conditions were maintained. During the basal contractile state, the mean heart rates did not vary $(85 \pm 8,85 \pm 8$, and $87 \pm 12$ beats/ $\mathrm{min}$ ), despite a range in left ventricular systolic pressure of 32 to $76 \mathrm{~mm} \mathrm{Hg}$ and in left ventricular enddiastolic pressure of 3 to $14 \mathrm{~mm} \mathrm{Hg}$ in each patient. Moreover, both (+)dP/dt $\max$ and $(+) \mathrm{dP} / \mathrm{dt} / \mathrm{DP}_{40}$ during the basal contractile state remained unchanged over this range of loading conditions $(1510 \pm 460,1870 \pm 769$, and $1558 \pm 291 \mathrm{~mm} \mathrm{Hg} /$ sec; and $1121 \pm 195,1250 \pm 260$, and $1213 \pm 238$ $\mathrm{mm} \mathrm{Hg} / \mathrm{sec}$, respectively). Similarly, during the enhanced contractile state, there was no significant change in mean heart rate $(90 \pm 11,93 \pm 9$, and $92 \pm 12$ beats $/ \mathrm{min}$ ), despite a range in left ventricular systolic pressure of 35 to $94 \mathrm{~mm} \mathrm{Hg}$ and in left 

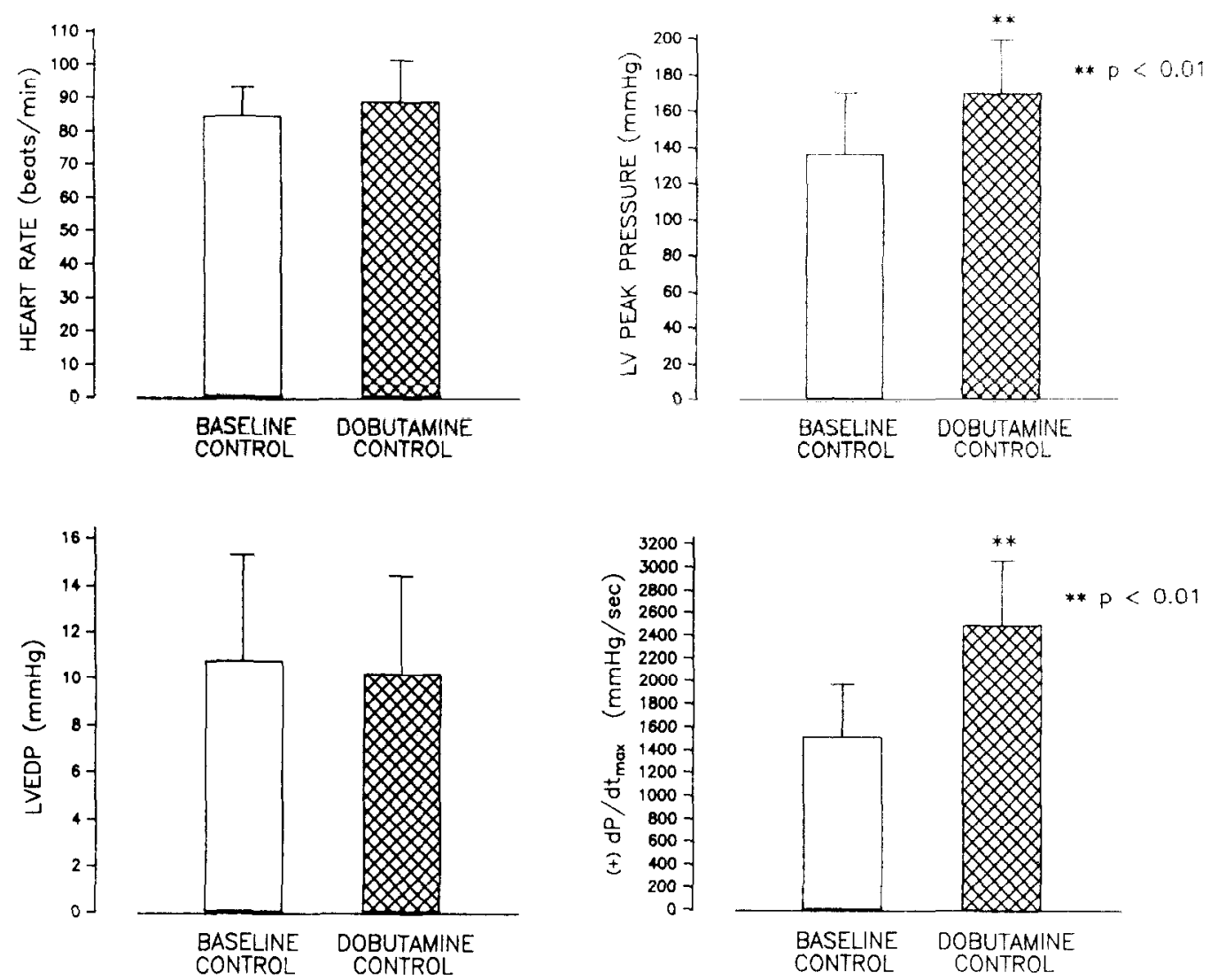

Fig. 2. The mean values for heart rate (upper left panel), left ventricular systolic pressure (upper right panel), left ventricular end-diastolic pressure (lower left panel), and left ventricular $(+) \mathrm{dP} / \mathrm{dt}_{\max }$ (lower right panel) during the basal (solid bars) and enhanced (open bars) contractile states are shown. Bars represent the mean plus 1 standard deviation. Significant differences are noted.

ventricular end-diastolic pressure of 2 to $10 \mathrm{~mm} \mathrm{Hg}$ in each patient. Importantly, despite significant increases in both $(+) \mathrm{dP} / \mathrm{dt}_{\max }$ and $(+) \mathrm{dP} / \mathrm{dt} / \mathrm{DP}_{40}$ during the dobutamine infusion in comparison with the basal contractile state, these measures did not vary significantly $(2537 \pm 546,2579 \pm 645$, and $2339 \pm 750 \mathrm{~mm} \mathrm{Hg} / \mathrm{sec} ;$ and $1714 \pm 277,2064 \pm 614$, and $1844 \pm 271 \mathrm{~mm} \mathrm{Hg} / \mathrm{sec}$, respectively) between loading conditions during the enhanced contractile state. Thus for both the basal and enhanced contractile states, a significant range in left ventricular pressures was produced by the methoxamine and nitroprusside infusions, but there was no significant effect on heart rate or on the isovolumic indices within each contractile state. Two different stable contractile states were therefore produced with a reasonable range of loading conditions to calculate the Emax slope values.

Response of isovolumic and ejection phase indices and $E_{\max }$ slope values to alterations in left ventricular contractile state. The left ventricular isovolumic and ejection phase indices were all increased during the enhanced compared with the basal contractile state. The left ventricular $(+) \mathrm{dP} / \mathrm{dt}_{\max }$ increased from $1510 \pm 460$ to $2537 \pm 546 \mathrm{~mm} \mathrm{Hg} / \mathrm{sec}(p<0.001)$, the $(+) \mathrm{dP} / \mathrm{dt}_{\text {max }} / \mathrm{EDV}$ increased from $15 \pm 7$ to $29 \pm 8 \mathrm{~mm} \mathrm{Hg} / \mathrm{sec} / \mathrm{ml}(p<0.001)$, and the $(+) \mathrm{dP} / \mathrm{dt} / \mathrm{DP}_{40}$ increased from $1121 \pm 195$ to $1714 \pm 277 \mathrm{~mm} \mathrm{Hg} / \mathrm{sec}(p<0.01)$.

The ejection phase indices were less sensitive to changes in left ventricular contractile state. The left ventricular ejection fraction increased from $55 \pm 14 \%$ to $62 \pm 15 \%(p<0.05)$, while the MSER only increased from $184 \pm 64$ to $223 \pm 106 \mathrm{ml} / \mathrm{sec}$ $(p=\mathrm{NS})$. The left ventricular SW only increased from $43 \pm 19$ to $55 \pm 18$ gram-meters $/ \mathrm{m}^{2}(p=N S)$, while the left ventricular SW normalized to end-diastolic volume (SW/EDV) increased from $0.37 \pm 0.10$ to $0.54 \pm 0.11$ gram-meters $/ \mathrm{m}^{2} / \mathrm{ml}(p<0.001)$.

The average $\mathrm{E}_{\max }$ slope value increased from $4.34 \pm 1.40 \mathrm{~mm} \mathrm{Hg} / \mathrm{ml}$ during the basal contractile state to $6.41 \pm 1.90 \mathrm{~mm} \mathrm{Hg} / \mathrm{ml}(p<0.001)$ during 


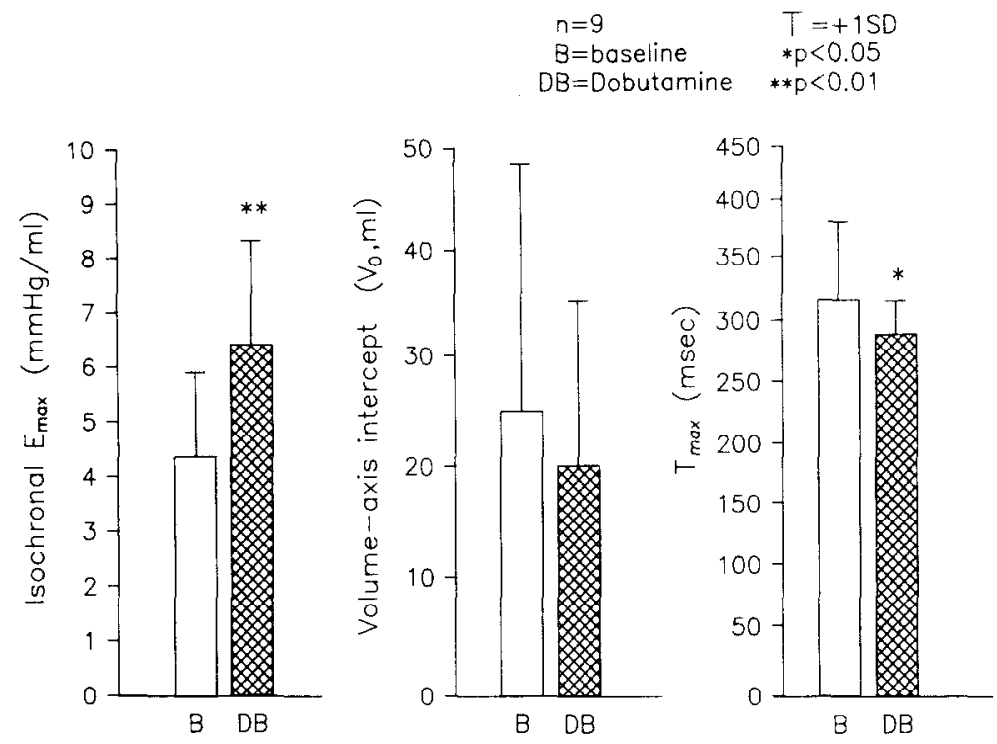

Fig. 3. Mean left ventricular isochronal $E_{\max }$ slope values (left panel), extrapolated volume-axis intercepts, $\mathrm{V}_{0}$ (center panel), and time to $\mathrm{E}_{\max }\left(\mathrm{T}_{\max }\right.$ ) values (right panel) are illustrated for the basal (solid bars) and enhanced (open bars) contractile states. Bars represent the mean plus 1 standard deviation. Significant differences are noted.

the dobutamine infusion. In contrast, the mean volume-axis intercept values did not differ significantly ( $25 \pm 23$ and $20 \pm 15 \mathrm{ml}$, respectively), while the time to $\mathrm{E}_{\max }\left(\mathrm{T}_{\max }\right)$ decreased from $328 \pm 26$ to $292 \pm 36 \mathrm{msec}(p=0.01)$. These data are illustrated in Fig. 3.

Relative responsiveness of indices of left ventricular contractility. The relative mean percent increases in each of the indices of left ventricular contractility are shown in Fig. 4. The mean percent increase in the $\mathrm{E}_{\max }$ slope values was $51 \pm 26 \%$. The mean percent increases in the ejection phase indices were, in general, less than that for $E_{\max }$. The left ventricular ejection fraction increased by only $11 \pm 14 \%$ $\left(p<0.001\right.$ versus $\left.\mathrm{E}_{\max }\right)$, while the mean percent increase in the MSER, SW, and SW/EDV were $21 \pm 39 \%, 40 \pm 53 \%$, and $53 \pm 37 \%$, respectively ( $p=$ NS versus Emax for all).

The mean percent increases in the isovolumic indices of left ventricular contractility were, in general, greater than that for $\mathrm{E}_{\max }$. The mean percent increase in $(+) \mathrm{dP} / \mathrm{dt}_{\max }$ was $77 \pm 47 \%$, while the mean percent increases in $(+) \mathrm{dP} / \mathrm{dt}_{\max } / \mathrm{EDV}$ and $(+) \mathrm{dP} / \mathrm{dt} / \mathrm{DP}_{40}$ were $112 \pm 93 \%$ and $57 \pm 39 \%$, respectively. The mean percent increase in the $\mathrm{E}_{\max }$ slope values was significantly less than those for $(+) \mathrm{dP} / \mathrm{dt}_{\max }$ and $(+) \mathrm{dP} / \mathrm{dt}_{\max } / \mathrm{EDV}(p<0.05$ for both), but it was similar to that for $(+) \mathrm{dP} / \mathrm{dt} / \mathrm{DP}_{40}$.

The percent changes in the $\mathrm{E}_{\max }$ slope values cor- related with the corresponding percent changes in $(+) \mathrm{dP} / \mathrm{dt}_{\max },(+) \mathrm{dP} / \mathrm{dt}_{\max } / \mathrm{EDV}$, and $(+) \mathrm{dP} / \mathrm{dt} / \mathrm{DP}_{40}$ $(r=0.79$ to $0.89, p=0.02$ to $p<0.01$ ). There was no correlation between the percent changes in the $\mathrm{E}_{\max }$ slope values and the corresponding percent changes in the ejection phase indices. When multiple regression analyses were employed, only the percent changes in $(+) \mathrm{dP} / \mathrm{dt} / \mathrm{DP}_{40}$ were independently related to the corresponding percent changes in the $\mathrm{E}_{\max }$ slope values. Notably, the percent changes in the $E_{\max }$ slope values and isovolumic indices of left ventricular contractility were comparably responsive to mild or moderate alterations in inotropic state.

There is no "gold standard" against which these indices can be compared to truly define their relative sensitivity to alterations in left ventricular contractility in man. However, an "ideal" contractile index should not be affected by confounding influences, which introduce significant measurement variability despite comparable alterations in left ventricular contractility. As shown in Fig. 4, not only do the mean percent changes differ, but also the variability in these percent change measurements differ. To account for these differences in measurement variability between contractile indices, the mean percent changes were divided by their corresponding standard deviations and the results were displayed in Fig. 5 . The relationship of the mean percent change in the $\mathrm{E}_{\max }$ slope values to those of the isovolumic and ejec- 


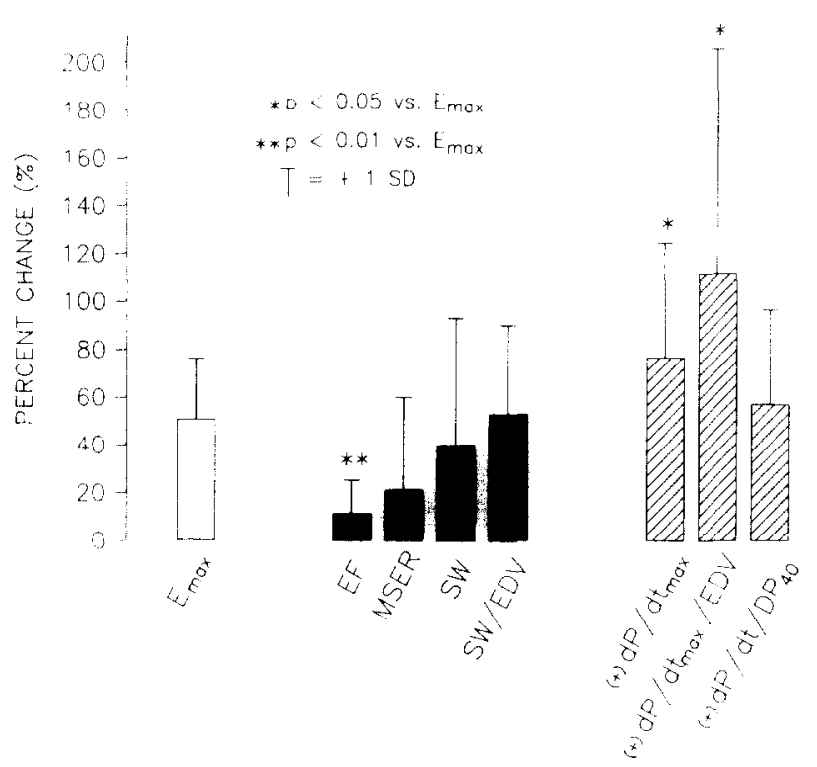

Fig. 4. The mean percent change in the $E_{\max }$ slope values $\left(E_{\text {max }}\right)$, left ventricular ejection fraction $(E F)$, mean systolic ejection rate (MSER), left ventricular stroke work $(S W)$, stroke work standardized to end-diastolic volume $(S W / E D V),(+) \mathrm{dP} / \mathrm{dt}_{\max },(+) \mathrm{dP} / \mathrm{dt}_{\max }$ standardized to end-diastolic volume $(E D V)$, and $(+) \mathrm{dP} / \mathrm{dt}$ at a common developed pressure of $40 \mathrm{~mm} \mathrm{Hg}\left(D P_{40}\right)$ are illustrated. Bars represent the mean plus 1 standard deviation. Significant differences from $\mathrm{E}_{\max }$ are illustrated.

tion phase indices has now changed, which suggests that there is less measurement variability in the time-varying elastance calculation compared with these isovolumic and ejection phase indices for comparable changes in left ventricular contractility. Presumably, this may be a representation of the relative load independence of the elastance approach to measuring changes in left ventricular contractility in contrast to that of the isovolumic and ejection phase indices. ${ }^{11-13}$

\section{DISCUSSION}

The present investigation demonstrates that $E_{\max }$ slope values calculated with radionuclide angiography are responsive to changes in left ventricular contractility in man. Importantly, the $\mathrm{E}_{\max }$ slope values were steeper and were achieved more quickly, but without an alteration in the volume-axis intercept during the enhanced contractile state compared with the basal contractile state. The mean percent change in the $\mathrm{E}_{\max }$ slope values was directionally and proportionally similar to those for the left ventricular isovolumic index $(+) \mathrm{dP} / \mathrm{dt} / \mathrm{DP}_{40}$ and for the ejection phase indices MSER, SW, and SW/EDV. The mean

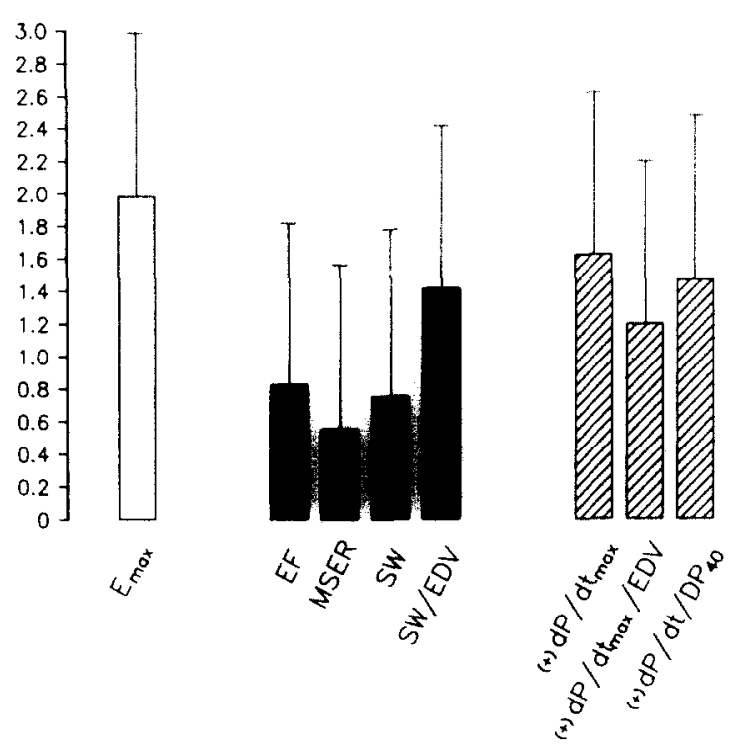

Fig. 5. The mean percent changes divided by their corresponding standard deviations are illustrated in a format similar to that used in Fig. 4. Note that the standard deviations are now all comparable due to incorporation of the measurement variability into the analysis. Essentially, the mean percent changes are now standardized by their corresponding errors so that comparisons in these indices of left ventricular contractility can be made on an equal basis.

percent change in the $\mathrm{E}_{\max }$ slope values was less than those for the isovolumic indices, $(+) \mathrm{dP} / \mathrm{dt}_{\max }$ and $(+) \mathrm{dP} / \mathrm{dt}_{\max } / \mathrm{EDV}$, but it was more than that for left ventricular ejection fraction. The percent changes in the $\mathrm{E}_{\max }$ slope values correlated with those for the isovolumic indices, and the only independent relationship existed between the corresponding percent changes in the $\mathrm{E}_{\max }$ slope values and $(+) \mathrm{dP} / \mathrm{dt} / \mathrm{DP}_{40}$. Moreover, the variability in the mean percent changes in the isovolumic and ejection phase indices was proportionately greater than that for the $\mathbf{E}_{\max }$ slope values. Consequently, when the variability in the percent changes for each of these indices of left ventricular contractility was incorporated into the analysis, the maximum time-varying elastance demonstrated a greater responsiveness to similar changes in left ventricular contractility compared with those of the isovolumic and ejection phase indices.

These observations in man are consistent with those originally reported by Suga and Sagawa ${ }^{2}$ concerning the response of the $\mathbf{E}_{\max }$ slope value to a $\beta$ adrenergic agonist. In an excised, supported left ventricular preparation, they demonstrated that the $\mathrm{E}_{\max }$ slope value occurred more quickly, had a steeper 
slope, and had no significant change in the volumeaxis intercept during a positive inotropic intervention. The response of the end-systolic P-V slope and volume-axis intercept $\left(\mathrm{V}_{0}\right)$ to a positive inotropic agent has, however, been reported to vary in animals. ${ }^{11,15-19}$ The slope and $V_{0}$ may either both increase $^{18}$; the slope may increase, while $V_{0}$ does not change ${ }^{15,17,18}$; the slope may increase, while the $V_{0}$ decreases ${ }^{11,16}$; or they may both be variably affected..$^{19}$ These different observations may be related to the preparations employed, the methods of generating the slope and $V_{0}$ values in these preparations, and the importance of intact autonomic reflexes. Nevertheless, the $\mathrm{E}_{\max }$ slope values demonstrated an increase without a change in $V_{0}$ in response to a positive inotropic intervention in our patients, which is similar to the original observations of Suga and Sagawa ${ }^{2}$ and of others. ${ }^{15,17}$

Kass et al. ${ }^{11}$ have demonstrated in an excised, supported left ventricular preparation that the end-systolic P-V slope values were relatively less responsive to changes in left ventricular contractility produced by intracoronary calcium or dobutamine than were isovolumic or ejection phase indices. In contrast, in a conscious animal preparation, Sodums et al. ${ }^{15}$ reported that the mean percent change in the end-systolic P-V slope values from a basal to an enhanced contractile state produced by an intravenous dobutamine infusion was less than the concomitant percent increase in $(+) \mathrm{dP} / \mathrm{dt}_{\text {max }}$, but both of these indices demonstrated greater percent changes than did left ventricular ejection fraction. The data from this investigation in man showed that the mean percent change in the $\mathrm{E}_{\max }$ slope values was in general less than those for the isovolumic indices of left ventricular contractility. Also, similar to the data reported by Sodums et al., ${ }^{15}$ the present study found the left ventricular ejection phase indices to be in general relatively less responsive to changes in contractility than the $\mathbf{E}_{\max }$ slope values or the isovolumic indices in man. Moreover, when the variability in the percent changes of each index was incorporated into the analysis, the maximum time-varying elastance demonstrated a greater responsiveness to changes in left ventricular contractility than these other indices in man.

There may be several possible explanations for the apparent differences in the reported relative responsiveness of these indices of left ventricular contractility between prior animal studies ${ }^{11,15}$ and the present investigation in man. First, the experimental preparations and the methods of altering load dif- fered. In the excised, supported left ventricular preparation, resistive afterload was altered by a three-element Windkessel model. ${ }^{11}$ Generation of these indices under highly controlled conditions such as these may produce results that differ from those obtained in intact animal preparations or man where load is altered either by inferior vena caval occlusion $^{15}$ or by pharmacologic means, ${ }^{4,6}$ as in the present investigation. Second, the route of administration and dose of dobutamine differed. In contrast to the previous animal studies where a fixed dose of dobutamine was administered by the intracoronary route or intravenously, ${ }^{11,15}$ different doses of dobutamine were given to vary the extent of the changes in left ventricular contractility between patients in this investigation. Thus by using graded doses of dobutamine in patients, not only the relative responsiveness but also interrelationships between the changes in these contractile indices could be defined. Third, the definition of the end-systolic $\mathrm{P}-\mathrm{V}$ relationship we employed in man differed from that used in the previous animal studies. ${ }^{11,15}$ The definition of end systole may not, however, explain the differences in the reported responsiveness of these indices to alterations in left ventricular contractility. Borow et al., ${ }^{20}$ employing $\mathrm{P}-\mathrm{V}$ slope values generated with an indirect carotid pulse tracing to obtain aortic dicrotic notch pressure and M-mode echocardiographic left ventricular volumes in man, reported a comparable mean percent change in the slope of these $P-V$ relations (approximately $55 \%$ ) to that observed in this investigation at a similar average dobutamine infusion. This was in spite of their use of a P-V relationship that has been shown to differ significantly from $\mathrm{E}_{\text {max }}$ in man. ${ }^{4,6}$ Finally, Kass et al. ${ }^{11}$ suggested that the relative percent change in the slope of the end-systolic P-V relationship in response to an inotropic intervention should be less than that for $(+) \mathrm{dP} / \mathrm{dt}_{\max }$, if $\mathrm{T}_{\max }$ and $\mathrm{V}_{0}$ are simultaneously reduced. In their excised, supported left ventricular preparation, they observed a significant decrease in both $T_{\max }$ and $V_{0}$ in association with a steeper slope of the end-systolic P-V relationship. ${ }^{11}$ In contrast, a steeper $E_{\max }$ slope value at a slightly reduced $T_{\max }$, but without a change in $V_{0}$, was observed in this investigation. Thus based on theoretic considerations, the percent increase in the $E_{\max }$ slope values observed in our patients should have been greater and closer to the percent changes in $(+) \mathrm{dP} / \mathrm{dt} \mathrm{t}_{\max }$ compared with those observed in the excised, supported left ventricle. ${ }^{11}$ These data suggest that the differences in the relative responsiveness of $E_{\max }$ slope values in 
comparison with isovolumic and ejection phase indices to alterations in left ventricular contractility reported in this and other studies ${ }^{11,15}$ may be dependent, in part, upon the preparations emplcyed, the rnethods of altering load to generate the $\mathrm{E}_{\max }$ slope values, and the specific response of the $\mathrm{E}_{\max }$ or endsystolic $\mathrm{P}-\mathrm{V}$ relationships to an inotropic intervention.

The data in the present investigation indicate that changes in the $\mathrm{E}_{\max }$ slope value may be more responsive to alterations in left ventricular contractility than other indices in man when the variability in these measurements is considered. This may be due to the greater impact of confounding influences, particularly loading condition, ${ }^{11-13}$ on the isovolumic and ejection phase indices in contrast to the relative load independence of the $\mathrm{E}_{\max }$ slope values. The $\mathrm{E}_{\max }$ slope values have, however, been shown to be inversely related to heart size in animals and patients without cardiac pathology. ${ }^{4,21}$ Berko et al. ${ }^{22}$ have demonstrated that an acute intervention, that significantly affects both end-systolic pressure-volume relations $\left(\mathrm{E}_{\mathrm{es}}\right)$ and heart size as measured by left ventricular end-diastolic volume, necessitates a correction of the $E_{\mathrm{es}}$ slope value for the change in heart size to establish whether an alteration in contractility has resulted. Notably, dobutamine produced no significant effect or left ventricular end-diastolic volume in our patients, and thus a correction for heart size was not felt to be necessary. Clearly, from this and other investigations, ${ }^{11,15-20}$ the time-varying elastance concept can be used to detect and quantitate acute changes in left ventricular contractility. Whether heart size can be or needs to be eliminated as a potential confounding influence in the $\mathrm{E}_{\max }$ slope values to be useful for detecting differences in contractile state between normal subjects and patients with cardiac pathology is unclear. ${ }^{23,}{ }^{24}$ Preliminary data from this laboratory ${ }^{24}$ suggest that heart size makes a relatively small contribution to the reduction in $\mathrm{E}_{\max }$ slope values observed over a wide range of left ventricular end-diastolic volumes. Consequently, $\mathrm{E}_{\max }$ slope values may be of particular importance in patients in whom isovolumic and ejection phase indices are preserved despite depressed contractile state, due to the favorable effects of loading conditions on these measures, such as in mitral regurgitation.

Potential limitations to the present investigation must be considered. There are several factors that may affect the calculation of the $\mathrm{E}_{\max }$ slope values in man including: heart rate,${ }^{7}$ coronary blood flow, ${ }^{25}$ re- gional myocardial ischemia, ${ }^{26,27}$ contraction sequence, ${ }^{28}$ vasoactive agents, ${ }^{15,29,30}$ and reflex neurohumoral activity. ${ }^{18}$ Heart rate was maintained constant by right atrial pacing in this investigation during both the basal and enhanced contractile states, and none of these patients had ischemic heart disease, which might produce regional contractile abnormalities. In addition, left ventricular systolic pressures were not reduced below the level that has been shown to produce an effect on these slope values. ${ }^{25}$ Moreover, these patients were all in normal sinus rhythm without conduction disturbances, and therefore a consideration of the effects of contraction sequence on the $\mathrm{E}_{\max }$ slope values was precluded. Thus by right atrial pacing, by avoiding patients with coronary artery disease, by careful manipulation of arterial load, and by restricting the study to those with a normal electrocardiogram, several of the potential confounding influences on the calculation of the $\mathrm{E}_{\max }$ slope values were not present in our patients.

All of the patients in this investigation were, however, studied with neurohumoral reflexes intact. Loading conditions were altered during the basal and enhanced contractile states using a combination of methoxamine or nitroprusside infusions. Sodums et al. ${ }^{15}$ have shown that an arterial vasoconstrictor, angiotensin II, shifts the end-systolic P-V relationship to a smaller $V_{0}$ without a change in slope from that observed during a control condition. This probably relates to the closer approximation of the isovolumic length-tension relationship when arterial load is increased. ${ }^{29}$ Nevertheless, these changes were small and were well within the potential variability of any volumetric technique used in man. Also, no significant change in the left ventricular $(+) \mathrm{dP} / \mathrm{dt}_{\max }$ and $(+) \mathrm{dP} / \mathrm{dt} / \mathrm{DP}_{40}$ values was observed over the range of loading conditions used, irrespective of whether it was during the basal or enhanced contractile states. Although reflex changes in autonomic tone during the prolonged infusion of these vasoactive agents cannot be completely excluded in these patients, these data suggest that two stable contractile states were maintained over the range of loading conditions employed, and that there was little effect of intact neurohumoral reflexes on the two contractile states. This is consistent with observations on the effects of changes in catecholamines on measures of left ventricular contractility in animals. ${ }^{31,32}$

In conclusion, the data from the present investigation indicate that the $E_{\max }$ slope values calculated with radionuclide angiography are responsive to 
acute alterations in left ventricular contractile state in man. When the measurement variability in the percent changes for each contractile index was incorporated into the analysis, the $\mathrm{E}_{\max }$ slope values appeared to be more responsive than the isovolumic and ejection phases indices to alterations in left ventricular contractility. This suggests that the $\mathrm{E}_{\max }$ slope value is a contractile index that is less affected by measurement variability than the isovolumic and ejection phase indices. This may reflect the relative load independence of the maximum time-varying elastance calculated using the present methodology compared to isovolumic and ejection phase indices of left ventricular contractility. Therefore the timevarying elastance concept may improve upon our ability to both detect and quantitate changes in left ventricular contractility in man. Whether long-term alterations in left ventricular contractile state can be similarly detected by changes in the $\mathrm{E}_{\max }$ slope values calculated with this method in man remains to be established.

The assistance of Sheila Squicciarini, Diane Bauer, and Penny Weaver in the preparation of this report is appreciated.

\section{REFERENCES}

1. Suga $H$, Sagawa $K$, Shoukas $\Lambda \Lambda$. Load independence of the instantaneous pressure-volume ratio of the canine left ventricle and effects of epinephrine and heart rate on the ratio. Circ Res 1973;32:314.

2. Suga $H$, Sagawa $K$. Instantaneous pressure-volume relationships and their ratio in the excised, supported canine left ventricle. Circ Res 1974;35:117.

3. Sagawa K. The ventricular pressure-volume diagram revisited. Circ Res 1978;43:677.

4. Starling MR, Walsh RA, Dell'Italia LJ, Mancini GBJ, Lasher JC, Lancaster JL. The relationship of various measures of end-systole to left ventricular maximum time-varying elastance in man. Circulation 1987;76:32.

5. McKay RG, Aroesty JM, Heller GV, Royal HD, Warren SE Grossman W. Assessment of the end-systolic pressure-volume relationship in human beings with the use of a time-varying elastance model. Circulation 1986;74:97.

6. Starling MR, Gross MD, Walsh RA, Dell'Italia LJ, Montgomery DG, Squicciarini SA, Blumhardt R. Assessment of the radionuclide angiographic left ventricular maximum timevarying elastance calculation in man. J Nucl Med 1988;29:1368.

7. Maughan WL, Sunagawa K, Burkhoff D, Graves WL, Hunter WC, Sagawa K. Effect of heart rate on the canine end-systolic pressure-volume relationship. Circulation 1985;72:654.

8. Starling MR, Dell'Italia LJ, Walsh RA, Little WC, Benedetto AR, Nusynowitz ML. Accurate estimates of absolute left ventricular volumes from equilibrium radionuclide angiographic count data using a simple geometric attenuation correction. J Am Coll Cardiol 1984;3:789.

9. Starling MR, Dell'Italia LJ, Nusynowitz ML, Walsh RA, Little WC, Benedetto AR. Estimates of left ventricular volumes by equilibrium radionuclide angiography: importance of attenuation correction. J Nucl Med 1984;25:14.

10. Dell'Italia LJ, Starling MR, Walsh RA, Badke FR, Lasher JC, Blumhardt R. Validation of attenuation-corrected equilibrium radionuclide angiographic determinations of right ven- tricular volume: comparison with cast-validated biplane cineventriculography. Circulation 1985;72:317.

11. Kass DA, Maughan WL, Guo ZM, Kono A, Sunagawa K, Sagawa K. Comparative influence of load versus inotropic states on indexes of ventricular contractility: experimental and theoretical analysis based on pressure-volume relationships. Circulation 1987;76:1422.

12. Mahler F, Ross J Jr, O'Rourke RA, Covell JW. Effects of changes in preload, afterload and inotropic state on ejection and isovolumic phase measures of contractility in the conscious dog. Am J Cardiol 1975;35:626.

13. Quinones MA, Gaasch WH, Alexander JK. Influence of acute changes in preload, afterload, contractile state and heart rate on ejection fraction and isovolumic indices of myocardial contractility in man. Circulation 1976;53:293.

14. Grossman W, ed. Cardiac catheterization and angiography. Appendix of normal values. Philadelphia: Lea \& Febiger, 1976:329.

15. Sodums MT, Badke FR, Starling MR, Little WC, O'Rourke RA. Evaluation of left ventricular contractile performance utilizing end-systolic pressure-volume relationships in conscious dogs. Circ Res 1984;54:731.

16. Paulus WJ, Claes VA, Brutsaert DL. End-systolic pressurevolume relation estimated from physiologically loaded cat papillary muscle contractions. Circ Res 1980;46:20.

17. Kaseda S, Tomoike H, Ogata I, Nakamura M. End-systolic pressure-volume, pressure-length, and stress-strain relations in canine hearts. Am J Physiol 1985;249:H648.

18. Spratt JA, Tyson GS, Glower DD, Davis JW, Muhlbaier LH, Olsen CO, Rankin JS. The end-systolic pressure-volume relationship in conscious dogs. Circulation 1987;75:1295.

19. Crottogini AJ, Willshaw P, Barra JG, Armentano R, Fischer EIC, Pichel RH. Inconsistency of the slope and the volume intercept of the end-systolic pressure-volume relationship as individual indexes of inotropic state in conscious dogs: presentation of an index combining both variables. Circulation 1987;76:1115.

20. Borow KM, Neumann A, Wynne J. Sensitivity of end-systolic pressure-volume relations to the inotropic state in humans. Circulation 1982;65:988.

21. Belcher P, Boerboom LE, Olinger GN. Standardization of end-systolic pressure-volume relation in the $\operatorname{dog}$. Am J Physiol 1985;249:H546.

22. Berko B, Gaasch WH, Tanigawa N, Smith D, Craige E. Disparity between ejection and end-systolic indexes of left ventricular contractility in mitral regurgitation. Circulation 1987;75:1310.

23. Mirsky I, Corin W.I, Murakami T, Grimm J, Hess OM, Krayenbuehl HP. Correction for preload in assessment of myocardial contractility in aortic and mitral valve disease: application of the concept of systolic myocardial stiffness. Circulation $1988 ; 78: 68$.

24. Hsia HH, Starling MR. Is it necessary to standardize left ventricular elastance for heart size? Circulation 1988;78:523.

25. Sunagawa K, Maughan WL, Friesinger G, Guzman P, Chang M-S, Sagawa K. Effects of coronary arterial pressure on left ventricular end-systolic pressure-volume relation of isolated canine heart. Circ Res 1982;50:727.

26. Sunagawa K, Maughan WL, Sagawa K. Effect of regional ischemia on the left ventricular end-systolic pressure-volume relationship of isolated canine hearts. Circ Res 1983;52: 170.

27. Little WC, O'Rourke RA. Effect of regional ischemia on the left ventricular end-systolic pressure-volume relation in chronically instrumented dogs. J Am Coll Cardiol 1985;5:297.

28. Park RC, Little WC, O'Rourke RA. Effect of alteration of left ventricular activation sequence on the left ventricular endsystolic pressure-volume relation in closed-chest dogs. Circ Res 1985;57:706.

29. Maughan WL, Sunagawa K, Burkhoff D, Sagawa K. Effect of 
arterial impedance changes on the end-systolic pressure volume relation. Circ Res 1984;54:595.

30. Freeman GI, Little WC, O'Rourke RA. The effect of vasoac tive agents on the left ventricular end-systolic pressurevolume relation in closed-chest dogs. Circulation 1986;74:1107.

31. Hintze TH, Vatner SF. Cardiac dynamies during hemorrhage: relative unimportance of adrenergic inotropic responses. Circ Res 1982;50:705.

32. Young MA, Hintze TH, Vatner SF. Correlation between cardiac performance and plasma catecholamine levels in conscious dogs. Am J Physiol 1985;248:H82.

\section{BOUND VOLUMES AVAILABLE TO SUBSCRIBERS}

Bound volumes of the AMERICAN HEART JOURNAL are available to subscribers (only) for the 1989 issues from the Publisher at a cost of $\$ 47.00$ ( $\$ 60.00$ international) for Vol. 117 (January-June) and Vol. 118 (July-December). Shipping charges are included. Each bound volume contains a subject and author index and all advertising is removed. Copies are shipped within 60 days after publication of the last issue in the volume. The binding is durable buckram with the journal name, volume number, and year stamped in gold on the spine. Payment must accompany all orders. Contact The C. V. Mosby Company, Circulation Department, 11830 Westline Industrial Drive, St. Louis, Missouri 63146, USA; phone (800) 325-4177, ext. 351.

Subscriptions must be in force to qualify. Bound volumes are not available in place of a regular Journal subscription. 